\title{
'n Vergelyking van die Mollusca-diversiteit in die Mooirivier (Noordwes-Provinsie) soos gevind met opnames wat gemaak is in 1963 en weer 50 jaar later
}

\begin{abstract}
Authors:
Cornelius T. Wolmarans ${ }^{1}$

Victor Wepener ${ }^{1}$

Uané Pretorius ${ }^{1}$

Johannes H. Erasmus ${ }^{1}$

Kenné N. de Kock ${ }^{1}$

\section{Affiliations:}

${ }^{1}$ Department of

Environmental Sciences and

Management, North-West

University, Potchefstroom

Campus, South Africa
\end{abstract}

Correspondence to:

Kenné de Kock

Email:

kenne.dekock@nwu.ac.za

Postal address:

Private Bag X6001,

Potchefstroom 2520,

South Africa

Dates:

Received: 16 Feb. 2015

Accepted: 12 May 2015

Published: 25 June 2015

How to cite this article:

Wolmarans, C.T., Wepener,

V., Pretorius, U., Erasmus,

J.H. \& De Kock, K.N., 2015, "n

Vergelyking van die Mollusca-

diversiteit in die Mooirivier

(Noordwes-Provinsie) soos

gevind met opnames wat

gemaak is in 1963 en weer

50 jaar later', Suid-Afrikaanse

Tydskrif vir Natuurwetenskap

en Tegnologie 34(1), Art.

\#1294, 7 pages. http://

dx.doi.org/10.4102/satnt.

v34i1.1294

\section{Copyright:}

(C) 2015. The Authors.

Licensee: AOSIS

OpenJournals. This work is

licensed under the Creative

Commons Attribution

License.

\section{Read online:}

Die hoogste getal gedokumenteerde uitsterwings van enige belangrike taksonomiese groep word aan die Mollusca toegedig. Faktore wat hoofsaaklik hiervoor verantwoordelik is, sluit onder meer omgewingsveranderinge en antropogeniese impakte in wat tot die tot niet gaan van die habitat aanleiding gee. Daarbenewens is die bewaringstatus van minder as $2 \%$ van die ongeveer 7000 molluskspesies wêreldwyd bekend tot dusver nog nie behoorlik geassesseer nie. Die doel van die huidige ondersoek wat in 2014 uitgevoer is, was om die molluskdiversiteit van die Mooirivier met die resultate van 1963 te vergelyk. Dit is gedoen deur 'n opname uit te voer van die molluskdiversiteit by dieselfde lokaliteite as in 1963 . Twee opnames is gemaak tydens 'n vroeë- en laatlaagvloeiperiode in 2014 by agt lokaliteite wat met dié van die 1963-opnames ooreenstem. Die pH, elektriese geleiding (EG) en temperatuur is ook by elk van die lokaliteite gemeet. Die identiteit van die 14 slakspesies wat in 1963 gevind is, het ooreengestem met 14 van die 15 in 2014. Die uitheemse indringerspesie Physa acuta is tydens die 2014-opname vir die eerste keer in hierdie rivier gevind, waarskynlik weens 'n toename in organiese verryking. In die 1963-opname is Burnupia mooiensis en Pisidium langlyanum by die meeste lokaliteite gevind, en in 2014 Gyraulus connollyi en Ferrissia cawstoni. Die meeste van die molluske uit hierdie gebied wat voorheen op rekord gestel is, is in 2014 gevind. Die pH wat in 2014 'n geringe tot aansienlike verlaging getoon het, word aan mynversuring toegeskryf en het nie 'n merkbare invloed op die molluskdiversiteit gehad nie. Die hoër elektriese geleiding wat tydens die 2014-opname gemeet is, het vanweë die verdraagsaamheid van varswatermolluske in hierdie verband, ook geen verandering in die molluskdiversiteit teweeg gebring nie. Die temperatuur was in die laatlaagvloei deurgaans hoër. Ondanks die feit dat hierdie studies vyf dekades uitmekaar gedoen is en antropogeniese impakte toegeneem het, is geen noemenswaardige verandering in die molluskdiversiteit waargeneem nie.

A comparison of the Mollusca diversity in the Mooi River (North-West Province) as found during surveys conducted in 1963 and again 50 years later. The highest number of documented extinctions of any major taxonomic group is ascribed to the Mollusca. Factors mainly responsible for this include environmental changes and anthropogenic impacts which result in habitat destruction. Furthermore, the conservation status of less than $2 \%$ of the more or less 7000 mollusc species, known worldwide, is still not properly assessed. The aim of the study done in 2014 was to assess the current status of the mollusc diversity in the Mooi River and to compare the results to the study done in 1963. The eight sites selected for this survey correspond with sites surveyed during the 1963 study, with surveys conducted during both an early and late low-flow period. The $\mathrm{pH}$, electrical conductivity (EC) and temperature were also measured at each locality. Of the 15 mollusc species collected in 2014, altogether 14 were the same as in the 1963 survey. However, an alien invasive species Physa acuta was additionally collected during the current survey, which is probably due to an increase in organic enrichment. During the 1963 survey Burnupia mooiensis and Pisidium langlyanum were present at most of the sites, while Gyraulus connollyi and Ferrissia cawstoni were found at six of the eight sites during the 2014 survey. Most of the molluscs previously recorded, were still present in 2014. With regard to the abiotic factors, the $\mathrm{pH}$ values recorded in 2014 showed a moderate to large decrease as compared to the 1963 survey. This acidification is ascribed to the development of gold mines in the adjacent area and apparently had little influence on the mollusc diversity. The increase in EC measured in 2014 did not have any influence on the diversity of the molluscs, probably due to their wide tolerance for this factor. As expected, the temperature measured in 2014 was markedly higher during the late low-flow period as compared to the early low-flow period. In conclusion, the differences discussed above revealed no obvious influence on the diversity of the freshwater molluscs over a 50 year period, despite increased anthropogenic impacts. 


\section{Inleiding}

Die wêreldwye afname in die diversiteit van varswaterorganismes is algemeen bekend. Volgens Dudgeon et al. (2006) is die uitsterwingskoers van varswaterorganismes so hoog soos $4 \%$ per dekade, wat nagenoeg vyf keer meer is as die verlies in terrestriële spesies. Daarbenewens dra faktore soos omgewingsveranderings, insluitende klimaatverandering en die storting van suur in varswateromgewings, verder by om die negatiewe impak van bogenoemde faktore te vererger.

Habitatvernietiging en -modifikasie sluit ontbossing, verstedeliking, landbou-aktiwiteite en rivieropdamming in (Van der Walt, Winde \& Nell 2002). Toevallige indringing en die doelbewuste vestiging van uitheemse spesies kom wêreldwyd voor, en die impak hiervan is groter by stelsels wat reeds deur die aktiwiteite van mense versteur is (Dudgeon et al. 2006). Hierdie toedrag van sake lei noodwendig tot ' $n$ verlies aan ekologiese integriteit van die habitat wat tot ' $n$ verdere afname in die diversiteit aanleiding kan gee. Die hoogste getal gedokumenteerde uitsterwings van enige belangrike taksonomiese groep word aan die Mollusca toegedig (Lydeard et al. 2004). Daarbenewens is die bewaringstatus van minder as $2 \%$ van die ongeveer 7000 Mollusca-spesies wêreldwyd bekend tot dusver nog nie behoorlik geassesseer nie (Lydeard et al. 2004).

Wat die Mooirivier in die Noordwes-Provinsie betref, is die eerste omvattende opname van varswatermolluske in 1963 uitgevoer en die bevindings in 1969 gepubliseer (De Kock \& Van Eeden 1969). Alhoewel die direkte omgewing van die opnamegebied tot op die hede oorwegend onveranderd gebly het, het faktore soos die toename in mynbou- en landbou-aktiwiteite tot 'n verhoging in die elektriese geleiding (EG) van die water gelei (Van der Walt et al. 2002; McCarthy 2011). Daarbenewens het die toename in bevolking tot ' $n$ verhoging in organiese besoedeling aanleiding gegee (Van der Walt et al. 2002). Hierdie bogenoemde faktore kon moontlik ' $n$ invloed op die Mollusca-diversiteit gehad het.

Die doel van die huidige ondersoek was om die Molluscadiversiteit, soos dit tans daar uitsien, te vergelyk met die resultate van die ondersoek wat in 1963 uitgevoer is (De Kock \& Van Eeden 1969) en om die moontlike impak te evalueer wat bogenoemde invloede kon hê. Dit is gedoen deur ' $n$ intensiewe opname van die Mollusca-diversiteit by dieselfde lokaliteite en deur van dieselfde metodes as in 1963 gebruik te maak.

\section{Materiaal en metodes Die studiegebied}

Bio-fisiese besonderhede van die lokaliteite waar opnames tydens hierdie ondersoek gedoen is, word in Tabel 1 weergegee en die ligging daarvan in Figuur 1 aangedui.

\section{Versamelapparaat en -tegnieke}

Twee opnames is in 2014 tydens 'n vroeë- en laatlaagvloeiperiode uitgevoer by agt lokaliteite wat met dié van die 1963-opnames ooreengestem het. Laagvloeiperiodes is vir beide die studies verkies omdat daar tydens hierdie tye minimale habitatversteurings voorkom. Molluske is versamel deur van 'n skepnet gebruik te maak wat bestaan het uit ' $n$ steel en 'n vierkantige aluminiumraamwerk van $30 \mathrm{~cm}$ waarop 'n vlekvrye staalsif met 'n maasgrootte van $1 \mathrm{~mm}$ aangebring is. Akwatiese en randplantegroei, sowel as

TABEL 1: Lokaliteite, habitatbeskrywings en landgebruike.

\begin{tabular}{|c|c|c|c|c|c|c|}
\hline Lokaliteit & Koördinate & Hoogte $(m)$ & Rivier & Habitat- en biotoopbeskrywings & Landgebruike & Dominante plantegroei \\
\hline Lokaliteit 1 & $\begin{array}{l}\text { S } 26^{\circ} 11^{\prime} 53.3^{\prime \prime} \\
\text { O } 27^{\circ} 09^{\prime} 53.1^{\prime \prime}\end{array}$ & 1472 & Bovensteoog & $\begin{array}{l}\text { Poel- en klipbevattende stroombedding, } \\
\text { rand- en akwatiese plante, asook } \\
\text { oorhangende oewerplantegroei. }\end{array}$ & $\begin{array}{l}\text { Gewasse en lewende } \\
\text { hawe. }\end{array}$ & $\begin{array}{l}\text { Berula erecta, Nymphaea nouchalia } \\
\text { var. caerulea, Typha capensis, } \\
\text { Veronica annagallis-aquatica, } \\
\text { Schoenoplectus corymbosus, } \\
\text { Nasturtium officinale. }\end{array}$ \\
\hline Lokaliteit 2 & $\begin{array}{l}\text { S } 26^{\circ} 15^{\prime} 11.3^{\prime \prime} \\
\text { O } 27^{\circ} 09^{\prime} 37.3^{\prime \prime}\end{array}$ & 1462 & $\begin{array}{l}\text { Mooirivier } \\
\text { onderkant } \\
\text { Klerkskraaldam }\end{array}$ & $\begin{array}{l}\text { Klipbevattende stroombedding, kabbel- en } \\
\text { rimpelstroom direk onderkant damwal, } \\
\text { rand- en akwatiese plante. }\end{array}$ & $\begin{array}{l}\text { Gewasse en lewende } \\
\text { hawe. }\end{array}$ & $\begin{array}{l}\text { Berula erecta, Juncus sp., Phragmites } \\
\text { mauritianus, Typha capensis, } \\
\text { Veronica annagallis- aquatica, } \\
\text { Rumex conglomeratus, Potomageton } \\
\text { pusillus, Potomageton schweinfurthii, } \\
\text { Nitella sp., Ludwigia natans. }\end{array}$ \\
\hline Lokaliteit 3 & $\begin{array}{l}\text { S } 26^{\circ} 21^{\prime} 35.5^{\prime \prime} \\
\text { O } 27^{\circ} 08^{\prime} 20.1^{\prime \prime}\end{array}$ & 1439 & $\begin{array}{l}\text { Mooirivier by } \\
\text { Rysmierbult }\end{array}$ & $\begin{array}{l}\text { Klipbevattende stroombedding, kabbel- en } \\
\text { rimpelstroom, sand- en moddersubstrate, } \\
\text { akwatiese en oorhangende oewerplante. }\end{array}$ & $\begin{array}{l}\text { Gewasse en lewende } \\
\text { hawe. }\end{array}$ & $\begin{array}{l}\text { Zygnema sp., Veronica annagallis- } \\
\text { aquatica, Ranunculus rionii, Ludwigia } \\
\text { natans, Plantago major. }\end{array}$ \\
\hline Lokaliteit 4 & $\begin{array}{l}\text { S } 26^{\circ} 26^{\prime} 43.1^{\prime \prime} \\
\text { O } 27^{\circ} 07^{\prime} 06.4^{\prime \prime}\end{array}$ & 1412 & $\begin{array}{l}\text { Mooirivier by } \\
\text { Muiskraal }\end{array}$ & $\begin{array}{l}\text { Klipbevattende stroombedding, kabbel- } \\
\text { en rimpelstroom, sandsubstraat, akwatiese } \\
\text { en oorhangende oewerplante. }\end{array}$ & $\begin{array}{l}\text { Gewasse en lewende } \\
\text { hawe. }\end{array}$ & $\begin{array}{l}\text { Typha capensis, Veronica } \\
\text { annagallis-aquatica, Schoenoplectus } \\
\text { corymbosus, Ludwigia natans, } \\
\text { Fissidens sp. }\end{array}$ \\
\hline Lokalitiet 5 & $\begin{array}{l}\text { S } 26^{\circ} 30^{\prime} 52.3^{\prime \prime} \\
\text { O } 27^{\circ} 07^{\prime} 28.5^{\prime \prime}\end{array}$ & 1399 & $\begin{array}{l}\text { Mooirivier bokant } \\
\text { Boskopdam }\end{array}$ & $\begin{array}{l}\text { Modder, rimpelstroom en poel, akwatiese } \\
\text { en oorhangende oewerplante. }\end{array}$ & $\begin{array}{l}\text { Gewasse en lewende } \\
\text { hawe. }\end{array}$ & $\begin{array}{l}\text { Phragmites mauritianus, Veronica } \\
\text { annagallis-aquatica, Nasturtium } \\
\text { officinale. }\end{array}$ \\
\hline Lokaliteit 6 & $\begin{array}{l}\text { S } 26^{\circ} 28^{\prime} 44.8^{\prime \prime} \\
\text { O } 27^{\circ} 09^{\prime} 03.4^{\prime \prime}\end{array}$ & 1415 & Gerhardminnebron & $\begin{array}{l}\text { Klipbevattende stroombedding, } \\
\text { oorwegend sand- en moddersubstraat, } \\
\text { akwatiese en oorhangende oewerplante. }\end{array}$ & $\begin{array}{l}\text { Gewasse en lewende } \\
\text { hawe. }\end{array}$ & $\begin{array}{l}\text { Berula erecta, Typha capensis, } \\
\text { Veronica annagallis-aquatica, } \\
\text { Ludwigia natans. }\end{array}$ \\
\hline Lokaliteit 7 & $\begin{array}{l}\text { S } 26^{\circ} 45^{\prime} 08.6^{\prime \prime} \\
\text { O } 27^{\circ} 06^{\prime} 01.2^{\prime \prime}\end{array}$ & 1324 & $\begin{array}{l}\text { Mooirivier by } \\
\text { Suidbrug }\end{array}$ & $\begin{array}{l}\text { Rimpelstroom en poel asook klei- } \\
\text { substraat, akwatiese en oorhangende } \\
\text { oewerplante. }\end{array}$ & $\begin{array}{l}\text { Stedelike, industriële } \\
\text { en landbou-aktiwiteite. }\end{array}$ & $\begin{array}{l}\text { Cyperus dives, Zygnema sp., } \\
\text { Phragmites mauritianus, Rumex } \\
\text { conglomeratus, Typha capensis. }\end{array}$ \\
\hline Lokaliteit 8 & $\begin{array}{l}\text { S } 26^{\circ} 52^{\prime} 50.2^{\prime \prime} \\
\text { O } 26^{\circ} 57^{\prime} 51.0^{\prime \prime}\end{array}$ & 1301 & $\begin{array}{l}\text { Mooirivier by } \\
\text { Kromdraai }\end{array}$ & $\begin{array}{l}\text { Kabbel- en rimpelstroombiotope } \\
\text { sandsubstraat, rand- en akwatiese plante, } \\
\text { oorhangende oewerplante. }\end{array}$ & $\begin{array}{l}\text { Gewasse en lewende } \\
\text { hawe. }\end{array}$ & $\begin{array}{l}\text { Cyperus dives, Zygnema sp., } \\
\text { Phragmites australis, Phragmites } \\
\text { mauritianus, Potamogeton pusillus, } \\
\text { Typha capensis, Veronica annagallis- } \\
\text { aquatica. }\end{array}$ \\
\hline
\end{tabular}




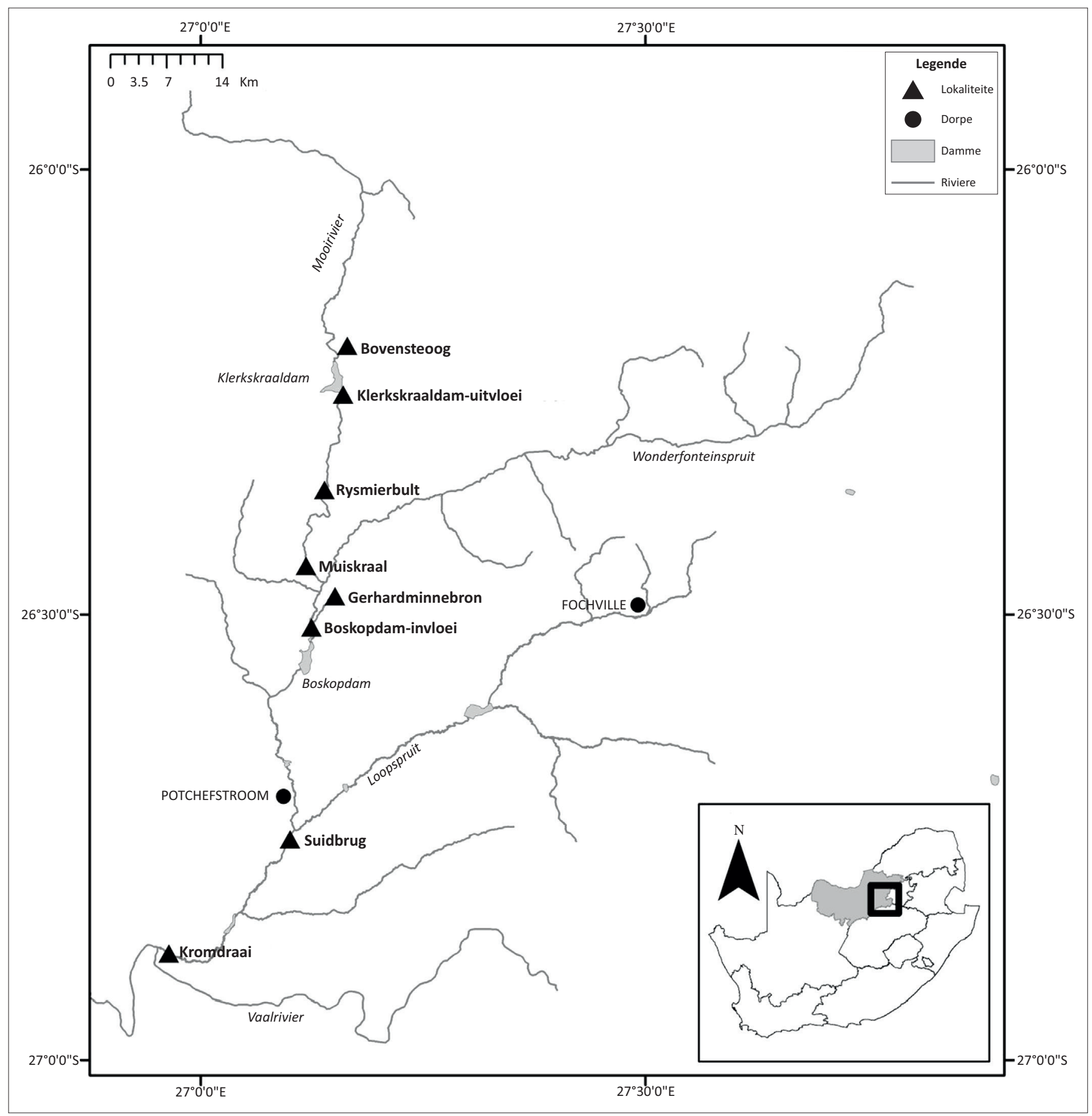

Bron: Die kaart van die studiegebied is deur Dr Wynand Malherbe opgestel met behulp van ArcGIS-sagteware

FIGUUR 1: Die studiegebied en lokaliteite waar molluske tydens die opnames in 1963 en 2014 versamel is.

al die substraattipes, is by elke lokaliteit ongeveer 45 minute lank met die skepnet versamel. Die inhoud van die skepnet is telkens oorgedra na 'n reghoekige, wit plastiekbak (360 mm x $470 \mathrm{~mm} \times 80 \mathrm{~mm}$ ) wat tot op 'n hoogte van ongeveer 40 $\mathrm{mm}$ met habitatwater gevul is. Alle growwe materiaal is vervolgens versigtig met die hand verwyder en vir molluske ondersoek (De Kock, Wolmarans, Kemp \& Roets 2013). Die inhoud van die plastiekbak is daarna gedekanteer in 'n kegelvormige net met ' $n$ maasgrootte van 0.25 mm wat op ' $n$ staander gesuspendeer is. Die inhoud van die net is daarna na 'n plastiekhouer met 'n digsluitende deksel oorgedra en 'n voldoende hoeveelheid $70 \%$ etanol bygevoeg om die monster te preserveer. 'n Etiket met die relevante besonderhede (lokaliteit, datum van versameling en koördinate) is buite op die houer aangebring. Monsters is daarna vir verdere verwerking na die laboratorium vervoer (De Kock et al. 2013).

Die koördinate en die hoogte bo seevlak van elke lokaliteit is met behulp van 'n Garmin Nuvi 500- GPS bepaal. Die EG, pH en temperatuur van die water is by alle lokaliteite met draagbare, digitale instrumente gemeet. Die temperatuurlesings gemeet in die 1963- studie is genoteer, maar slegs aangewend vir die berekening van EG. Spesies van dominante akwatiese en randplante is met behulp van 
gidse soos Joska en Bolton (1995), Gerber et al. (2004) en Van Ginkel et al. (2011) geïdentifiseer en aangeteken.

In die laboratorium is die molluske met behulp van 'n stereo-mikroskoop gemonteer op 'n skuiftafel ondersoek en voorlopig gesorteer. Elke groep is daarna in 'n glasflessie van $100 \mathrm{~mL}$ met 'n digsluitende skroefdeksel geplaas en $70 \%$ etanol as preserveermiddel bygevoeg. Identifikasie tot op spesievlak is daarna gedoen.

\section{Statistiese verwerking}

'n Hoofkomponent-analise (HKA) is gedoen om die resultate te ontleed.

\section{Resultate}

Tabel 2 toon dat daar in 1963 altesaam 14 en in 2014 altesaam 15 molluskspesies in die betrokke lokaliteite gevind is. In 2014 is al die spesies weer gevind wat in die 1963-ondersoek gerapporteer is. Die uitheemse indringerspesie Physa acuta, wat nie tydens die 1963-ondersoek gevind is nie, is egter in 2014 by verskeie lokaliteite aangetref. Dit is verder opvallend dat geen noemenswaardige verskille in die diversiteit, soos vasgestel tydens die vroeë- en laatlaagvloeiperiodes in beide studies, voorgekom het nie.

Wat die diversiteit per lokaliteit (L) betref, het aansienlike variasie tussen die 1963- en 2014-opnames voorgekom. By L 1 is Ceratophallus natalensis en Ferrissia cawstoni nie tydens die 2014-opnames gevind nie, terwyl Pisidium langleyanum nie by $\mathrm{L} 2$ gevind is nie. In teenstelling hiermee is Bulinus tropicus, Gyraulus costulatus, Gyraulus connollyi en Corbicula fluminalis africana slegs in 2014 by L 2 gevind (Tabel 2). Wat L 3 betref, is G. costulatus, Burnupia mooiensis en Pisidium viridarium net gedurende die 1963-opnames gevind, terwyl B. tropicus, C. natalensis en P. acuta addisioneel in 2014 gevind is. Betreffende L 4, is dit duidelik dat die diversiteit daarvan die meeste van die 1963-opname verskil het, deurdat agt addisionele spesies gedurende 2014 gevind is, wat G. costulatus, G. connollyi, F. cawstoni, C. fluminalis africana, Pisidium costulosum, $P$. langleyanum, $P$. viridarium en $P$. acuta ingesluit het (Tabel 2). Lymnaea truncatula, wat nie in 2014 by hierdie lokaliteit gevind is nie, is egter in 1963 hier aangetref. Dit is egter belangrik om daarop te wys dat daar gedurende 1963 net 'n vroeëlaagvloei-opname gemaak is weens gebrek aan water in die rivier gedurende die laatlaagvloei-periode. Opnames wat gedurende 1963 en 2014 by L 5 gedoen is, het getoon dat B. tropicus en C. natalensis nie gedurende 2014 gevind is nie, terwyl G. connollyi, F. cawstoni en P. costulosum nie gedurende 1963 aangetref is nie. Ferrissia cawstoni is by L 6 slegs gedurende die 2014-opname aangetref, terwyl L. truncatula, Bulinus africanus, B. mooiensis en P. langleyanum net gedurende 1963 gevind is. Bulinus tropicus, G. connollyi, F. cawstoni, P. viridarium en P. acuta is net tydens 2014 by L 7 gevind. Lokaliteit 8 het, naas L 1, die minste variasie in diversiteit getoon. In hierdie geval is L. truncatula en $P$. langleyanum slegs gedurende 1963 aangetref, terwyl F. cawstoni en P. acuta addisioneel net in 2014 gevind is.
Betreffende die molluskspesies wat tydens 1963 en 2014 gedomineer het, is dit opvallend dat P. langleyanum en B. mooiensis by die meeste lokaliteite voorgekom het. Dit is verder duidelik dat C. natalensis, L. truncatula en L. natalensis gedurende die opname in 1963 respektiewelik by vyf, vier en vier lokaliteite gevind is, terwyl G. connollyi en F. cawstoni beide tydens die opname in 2014 by ses van die agt lokaliteite gevind is. Die totale diversiteit vir al twee studies was in al die lokaliteite, afgesien van L 1 en 6, gedurende die 2014-ondersoek hoër as tydens die 1963-ondersoek, maar was tydens beide ondersoeke by L 8 eenders (aangedui as getal spesies per jaar in Tabel 2). Alhoewel daar aansienlike variasie in die spesierykheid by die verskillende lokaliteite voorgekom het, is die meeste spesies tydens beide opnames oorwegend by L 8 gevind. Dit is verder opvallend dat die kleinste diversiteit gedurende die 2014-opnames by die Bovensteoog (L 1) en die Gerhardminnebron (L 6) gevind is. In teenstelling hiermee, is die tweede hoogste diversiteit in 1963 by hierdie twee bronne aangetref.

Die statistiese verwerking van die assosiasies tussen die varswatermolluske, bepaalde lokaliteite en abiotiese faktore, word in Figuur 2 weergegee. Hieruit is dit duidelik dat daar 'n assosiasie tussen L. truncatula en L 3 in 1963, asook gedurende die 2014-opname voorgekom het (linkerkantste boonste kwadrant). In teenstelling hiermee het B. tropicus en P. acuta in 2014 met L 7 geassosieer, en B. tropicus in 1963 ook met L8 (regterkantste boonste kwadrant). Corbicula fluminalis het in 2014 (regterkantste onderste kwadrant) met EG en L 8 geassosieer. In 2014 het G. connollyi met L 4 en L 5, en B. mooiensis met L 2 en L 5 geassosieer (regterkantste onderste kwadrant). Assosiasies tussen G. costulatus met L 1 in 2014, en L 3 in 1963; L. natalensis met L 1 in 1963 en 2014; en B. africanus met L 1 (1963 en 2014) asook L 6 is in 1963 gevind (linkerkantste onderste kwadrant).

Wat die abiotiese faktore betref, toon die $\mathrm{pH}$ 'n geringe tot aansienlike verlaging in die 2014- opnames, terwyl die EG deurgaans byna verdubbel het (Tabel 2). Dit is verder duidelik dat die gemete temperatuur tydens die laatlaagvloeiperiode deurgaans hoër was as tydens die vroeë-laagvloeiperiodes.

Figuur 2 toon dat die $\mathrm{pH}$ ewe veel met Faktor 1 en 2 geassosieer het (regterkantste onderste kwadrant), terwyl EG in dieselfde kwadrant met Faktor 1 geassosieer het.

Betreffende die randplantegroei is daar 'n merkbare verdigting van Phragmites mauritianus en Typha capensis waarneembaar by die meerderheid van die lokaliteite in vergelyking met die opname in 1963 wat deur De Kock en Van Eeden (1969) gerapporteer is. Met die uitsondering van die uitheemse spesie Pontederia cordata wat in die 2014-opname by Gerhardminnebron aangetref is en deur Gerber et al. (2004) as 'n moontlike probleemspesie gelys word, is daar oor die algemeen geen noemenswaardige verskille in die voorkoms van akwatiese plante soos tydens die 1963-opname waargeneem nie. 


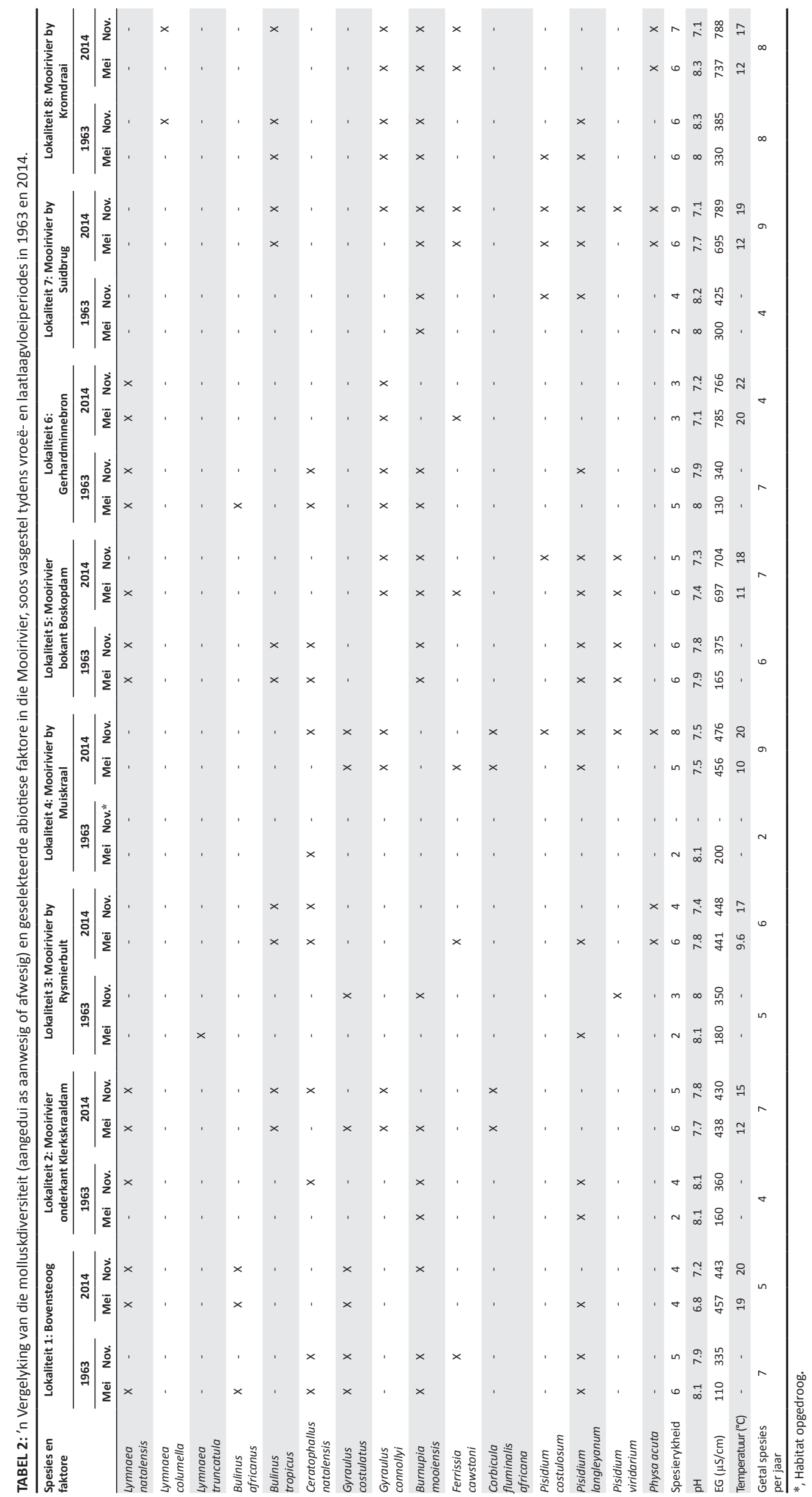




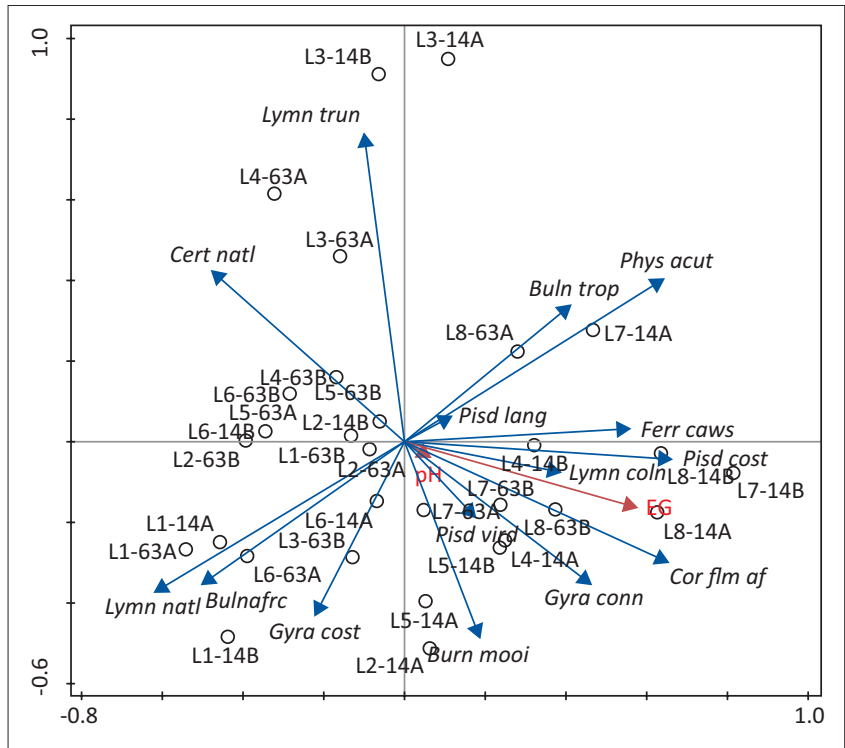

Bron: Die hoofkomponentanalise is met behulp van Canoco 5-sagteware gegenereer

FIGUUR 2: 'n Hoofkomponentanalise van die verskillende molluskspesies by die geselekteerde lokaliteite (L), jaar van opname: 1963 (63), 2014 (14), vroeëlaagvloei-opname (A), laatlaagvloei-opname (B), elektriese geleiding (EG) en pH. Faktor 1 verduidelik $21.2 \%$ en Faktor 2 verduidelik $13.3 \%$ van die variansie in die datastel.

\section{Bespreking}

Uit die databasis van die Nasionale Varswaterslakversameling is dit duidelik dat die meerderheid spesies wat tussen 1958 en 1963 tydens mollusk-opnames opgeteken is, weer in die ooreenstemmende geografiese areas aangetref is. Bulinus forskalii, B. reticulatus, Unio caffra en Burnupia transvaalensis wat wel voorheen in hierdie geografiese gebied gevind is, is nie in die 1963- of 2014-ondersoeke aangetref nie. Eersgenoemde twee molluske is spesies wat volgens Brown (1994), De Kock et al. (2002) en De Kock en Wolmarans (2005) hoofsaaklik tot tydelike habitats beperk is, terwyl U. caffra in 'n lokaliteit gevind is wat nie in die huidige studie ondersoek is nie. Burnupia transvaalensis is voorheen slegs in uitsonderlike gevalle aangetref en derhalwe is dit nie onverwags dat dit nie in die huidige ondersoek gevind is nie.

Alhoewel die habitat in 1963 geskik was vir P. acuta, algemeen as die rioolslak bekend (De Kock \& Wolmarans 2007), maar by geen van die lokaliteite aangetref is nie, word die voorkoms daarvan in die 2014-opname hoofsaaklik aan organiese verryking toegeskryf. Hierdie afleiding word gestaaf deur die assosiasie soos deur die HKA by L 7 (Figuur 2) aangedui. Hierdie organiese verryking is hoofsaaklik toe te skryf aan die verdigting en toename in formele en informele nedersettings in die opvangsgebied van die Mooirivier, wat die Wonderfonteinspruit, Loopspruit en Wasgoedspruit insluit (Van der Walt et al. 2002). Hierdie omstandigheid kan waarskynlik ook dien as verklaring vir die assosiasies van B. tropicus met L 8 in 1963, en met L 7 in 2014 (Figuur 2). Die sporadiese toename in Escherichia coli in hierdie gebiede weens gebrekkige rioolverwerking in hoofsaaklik die informele nedersettings (Nell 2014) is verdere stawing van dié bevinding. Die toename in diversiteit by die meeste lokaliteite in die 2014-studie kan moontlik ook aan organiese verryking toegeskryf word (Brown 1994; Ndifon \& Ukoli 1989; Thomas \& Daldorph 1994). Die relatiewe hoë diversiteit wat by $\mathrm{L} 8$ gevind is, wat onder meer ook $P$. acuta ingesluit het, kan waarskynlik ook toegeskryf word aan die organies verrykende invloed van die Wasgoedspruit, wat in die Mooirivier in die sentrale gebied van Potchefstroom vanuit die naasliggende nedersettings dreineer (Annandale \& Nealer 2011). Daarbenewens dra die Potchefstroomrioolwerk, asook dié by Loopspruit waarskynlik tot hierdie verryking by.

Daarteenoor was die beperkte diversiteit wat in 2014 by beide die bronne (Bovensteoog en Gerhardminnebron) gevind is en veral die afwesigheid van P. acuta by hierdie lokaliteite, waarskynlik aan beperkte nutriënte toe te skryf. 'n Moontlike verklaring vir 'n tekort aan nutriënte kan waarskynlik aan die omstandigheid toegeskryf word dat beide fonteine vir 'n geruime tyd reeds afgekamp is en derhalwe net vir kleiner soogdiere toeganklik is. Daarbenewens ontvang hierdie oë ook nie water van die geïmpakteerde Wonderfonteinspruit nie. In teenstelling hiermee was die diversiteit by hierdie lokaliteite tydens die 1963-opnames hoër, toe die fonteine ook vir veesuiping en die omgewing vir weiding benut is en dit tot verryking van die water kon bydra.

Wat die toename in voorkoms van B. mooiensis, G. connollyi en $C$. natalensis in meerdere lokaliteite betref, is hierdie spesies in staat om nisse op die bodem, asook in akwatieseen randplante te benut (Brown 1994; De Kock \& Wolmarans 2004), terwyl P. langleyanum uitsluitlik nisse op die bodem benut (De Kock \& Van Eeden 1969; De Kock \& Wolmarans 2008). Hierdie eienskappe stel die genoemde molluske in staat om die meeste fisiese habitatversteurings te oorkom. Wat B. mooiensis betref, word die HKA-assosiasie, soos aangedui by L 2 en L 5 in 2014, aan die dominerende, stadig vloeiende rimpelstrome toegeskryf (De Kock \& Wolmarans 2009). Die assosiasie van G. connollyi net met L 4 en L 5 kan nie verklaar word nie, omdat hierdie spesie vanweë die beskikbaarheid van geskikte habitats (De Kock \& Wolmarans 2004) ook by verskillende ander lokaliteite aangetref is. Die statistiese assosiasie van L. natalensis met $\mathrm{L} 1$ word hoofsaaklik aan die behoefte aan permanente, relatief skoon water toegeskryf (De Kock et al. 2001). Die teenwoordigheid van B. africanus by beide die oë (L 1 en L 6) word uitsluitlik toegeskryf aan die beperkte seisoenale en dag-nag-skommeling in temperatuur (De Kock \& Van Eeden 1969). Ceratophallus natalensis het ewe veel met Faktor 1 en 2 geassosieer, terwyl L. truncatula sterker met Faktor 2 geassosieer het (Figuur 2). Die molluskspesies wat nie spesifieke statistiese assosiasies getoon het nie, is nie verder bespreek nie.

Die laer waargeneemde $\mathrm{pH}$-waardes wat tydens die 2014-opnames gemeet is en wat hoofsaaklik aan mynversuring toegeskryf kan word (McCarthy 2011; Van der Walt et al. 2002), het nie 'n merkbare invloed op die molluskdiversiteit getoon nie. Dit is in ooreenstemming 
met die bevindinge elders met ander molluskspesies, soos byvoorbeeld in Engeland (Boycot 1936), Egipte en Soedan (Abdel-Malek 1956) en in Mpumalanga (Schutte \& Frank 1964). Die hoër EG wat tydens die 2014-opnames gemeet is, is die resultaat van die akkumulasie van sulfate en fosfate sedert 1969, weens goudmynverwante bedrywighede (Barnard, Venter \& Van Ginkel 2013; McCarthy 2011), asook landbouaktiwiteite (Van der Walt et al. 2002). Die afwesigheid van merkbare verandering in die molluskdiversiteit kan moontlik toegeskryf word aan die reeds bekende verdraagsaamheid wat varswatermolluske ten opsigte van EG toon (Brown 1994; Schutte \& Frank 1964).

Om op te som, is dit duidelik dat, ondanks die feit dat hierdie studies meer as vyf dekades uitmekaar gedoen is waartydens aansienlike verstedeliking, toename in informele nedersettings en industriële ontwikkeling plaasgevind het (Annandale \& Nealer 2011; Van der Walt et al. 2002), geen noemenswaardige verandering in die molluskdiversiteit waargeneem is nie. Die hoofrede hiervoor is waarskynlik die algemene verdraagsaamheid wat hierdie diergroep teenoor 'n verskeidenheid van omgewingsfaktore toon.

\section{Erkenning}

Die Eenheid vir Omgewingswetenskappe en -Bestuur van die Potchefstroomkampus van die Noordwes-Universiteit vir finansiële steun en beskikbaarstelling van infrastruktuur. Ons opregte dank en waardering word hiermee betuig aan dr. Wynand Malherbe vir die gedetailleerde kaart van die studiegebied, me. M. Kemp vir die hulp met statistiese verwerking, asook mnr. Ben Nell vir die beskikbaarstelling van data.

\section{Mededingende belange}

Die outeurs verklaar hiermee dat hulle geen finansiële of persoonlike verbintenis het met enige party wat hulle nadelig of voordelig in die skryf van hierdie artikel kon beïnvloed het nie.

\section{Outeursbydrae}

K.N.d.K. (Noordwes-Universiteit) was betrokke by die beplanning van die projek, die versameling van die Mollusca en het die monsters geïdentifiseer. Hy was betrokke by die verwerking van die resultate, asook by die beplanning, skryf en versorging van die manuskrip. J.H.E. (Noordwes-Universiteit), U.P. (Noordwes-Universiteit), V.W. (Noordwes-Universiteit) en C.T.W. (NoordwesUniversiteit) was betrokke by die beplanning van die projek, die versameling van die Mollusca, die verwerking van die resultate, asook die beplanning en skryf van die manuskrip.

\section{Literatuurverwysings}

Abdel-Malek, E.T., 1956, 'Factors conditioning the habitat of bilharziasis intermediate hosts of the family Planorbidae', Bulletin of the World Health Organization 26, 1-51. Annandale, E. \& Nealer, E., 2011, 'Exploring aspects of the water history of the Potchefstroom region and the local management of it', New Contree 62, 111-124.

Barnard, S., Venter, A. \& Van Ginkel, C.E., 2013, 'Overview of the influences of miningrelated pollution on the water quality of the Mooi River system's reservoirs, using basic statistical analyses and self-organised mapping', Water SA 39(5), 655-662. http://dx.doi.org/10.4314/wsa.v39i5.10

Boycot, A.E., 1936, 'The habitats of freshwater Mollusca in Britain', Journal of Animal Ecology 5, 116-186. http://dx.doi.org/10.2307/1096

Brown, D.S., 1994, Freshwater snails of Africa and their medical importance, revised 2nd edn., Taylor \& Francis, London.

De Kock, K.N. \& Van Eeden, J.A., 1969, 'Die verspreiding en habitatseleksie van die Mollusca in die Mooirivier, Transvaal', Wetenskaplike Bydraes van die PU vir $\mathrm{CHO}$ Reeks B: Natuurwetenskappe 8, 1-119.

De Kock, K.N. \& Wolmarans, C.T., 2004, 'Verspreiding en habitats van Gyraulus connollyi, slaktussengasheer van ingewandsbotte van die familie Echinostomatidae, in SuidAfrika', Suid-Afrikaanse Tydskrif vir Natuurwetenskap en Tegnologie 23(3), 79-86. http://dx.doi.org/10.4102/satnt.v23i3.196

De Kock, K.N. \& Wolmarans, C.T., 2005, 'Distribution, habitats and role as intermediate host of the freshwater snail, Bulinus forskalii, in South Africa', Onderstepoort Journa of Veterinary Research 72, 165-174. http://dx.doi.org/10.4102/ojvr.v72i2.214

De Kock, K.N. \& Wolmarans, C.T., 2007, 'Distribution and habitats of the alien invader freshwater snail Physa acuta in South Africa', Water SA 33(5), 719-724.

De Kock, K.N. \& Wolmarans, C.T., 2008, 'Distribution of the pill clam Pisidium langleyanum Melvill \& Ponsonby, 1891 (Bivalvia: Sphaeriidae) in South Africa', Water SA 34(5), 623-630.

De Kock, K.N. \& Wolmarans, C.T., 2009, 'Verspreiding van Burnupia capensis (Walker 1912) en Burnupia stenochorias (Melvill \& Ponsonby 1903) (Gastropoda: Ancylidae) in Suid-Afrika', Suid-Afrikaanse Tydskrif vir Natuurwetenskap en Tegnologie 28(3), 220-235. http://dx.doi.org/10.4102/satnt.v28i3.59

De Kock, K.N., Wolmarans, C.T., Kemp, M. \& Roets, W., 2013, 'Korttermynbedreigings vir varswater-Mollusca in die Olifantsrivier en enkele sytakke', Suid-Afrikaanse Tydskrif vir Natuurwetenskap en Tegnologie 32(1), Art. \#395, 6 pages. http:// dx.doi. org/10.4102/satnt.v32i1.395

De Kock, K.N., Wolmarans, C.T., Strauss, H.D. \& Killian, M., 2001, 'Verspreiding en habitats van Lymnaea natalensis, tussengasheerslak van die lewerbot Fasciola gigantica in Suid-Afrika', Suid-Afrikaanse Tydskrif vir Natuurwetenskap en Tegnologie 20(2), 49-53. http://dx.doi.org/10.4102/satnt.v20i2.251

De Kock, K.N., Wolmarans, C.T., Strauss, H.D., Killian, M. \& Maree, D.C., 2002 'Geographical distribution and habitats of the freshwater snail Bulinus reticulatus and its susceptibility to Schistosoma haematobium miracidia under experimental and its susceptibility to Schistosoma haem
conditions', African Zoology 37(1), 1-6.

Dudgeon, D., Arthington, A.H., Gessner, M.O., Kawabata, Z.-I., Knowler, D.J., Lévêque, C. et al., 2006, 'Freshwater biodiversity: Importance, threats, status and conservation challenges', Biological Reviews 81, 163-182. http://dx.doi. org $/ 10.1017 /$ S1464793105006950

Gerber, A., Cilliers, C.J., Van Ginkel, C. \& Glen, R., 2004, Easy identification of aquatic plants, Department of Water Affairs and Forestry, Pretoria.

Joska, M.A. \& Bolton, J.J., 1995, Guide to common filamentous freshwater macro-algae in South Africa, Water Research Commission Project number K5/426, Pretoria.

Lydeard, C., Cowie, R.H., Ponder, W.F., Bogan, A.E., Bouchet, P., Clark, S.A. et al., 2004 , 'The global decline of nonmarine mollusks', BioScience 54, 321-330. http://dx.doi. org/10.1641/0006-3568(2004)054[0321:TGDONM]2.0.CO;2

McCarthy, T.S., 2011, 'The impact of acid mine drainage in South Africa', South African Journal of Science 107(5/6), 1-7. http://dx.doi.org/10.4102/sajs.v107i5/6.712

Ndifon, G.T. \& Ukoli, F.M.A., 1989, 'Ecology of freshwater snails in south-western Nigeria, I: Distribution and habitat preferences', Hydrobiologia 171(3), 231-253. http://dx.doi.org/10.1007/BF00008146

Nell, B., 2014, Persoonlike mededeling (Hoofchemikus, Potchefstroomse Stadsraad).

Schutte, C.H.J. \& Frank, G.H., 1964, 'Observations on the distribution of freshwater Mollusca and chemistry of the natural waters in the south-eastern Transvaal and adjacent northern Swaziland', Bulletin of the World Health Organization 30, 389-400.

Thomas, J.D. \& Daldorph, P.W.G., 1994, 'The influence of nutrient and organic enrichment on a community dominated by macrophytes and gastropod molluscs in a eutrophic drainage channel: relevance to snail control and conservation', Journal of Applied Ecology 31(3), 571-588. http://dx.doi.org/10.2307/2404451

Van der Walt, I.J., Winde, F. \& Nell, B., 2002, 'Integrated catchment management: The Mooi River (Northwest Province, South Africa) as a case study', Cuadernos de Investigacion Geografica 28, 109-126. http://dx.doi.org/10.18172/cig.1131

Van Ginkel, C.E., Glen, R.P., Gordon-Gray, K.D., Cilliers, C.J., Muasya M. \& Van Deventer P.P., 2011, Easy identification of some South African wetland plants (grasses, restios, sedges, rushes, bulrushes, eriocaulons and yellow-eyed grasses), Water Research Commission Report No TT 479/10, Pretoria. 